\title{
Aktifitas Fisik, Riwayat Dismenore Keluarga dan Kecemasan dengan Dismenore pada Remaja
}

\author{
Elis Diana Putri ${ }^{1}$, Aprilya Nency ${ }^{2}$ \\ ${ }^{1,2}$ Program Studi Kebidanan Program Sarjana Terapan \\ Sekolah Tinggi Ilmu Kesehatan Indonesia Maju
}

Jln. Harapan No. 50, Lenteng Agung, Jakarta Selatan - Indonesia

Email: ${ }^{1}$ dianaelis594@gmail.com, ${ }^{2}$ aprilyanency@gmail.com

Editor: H, Nina

Hak Cipta:

(C)2021 Artikel ini memiliki akses terbuka dan dapat didistribusikan berdasarkan ketentuan Lisensi Atribusi Creative Commons, yang memungkinkan penggunaan, distribusi, dan reproduksi yang tidak dibatasi dalam media apa pun, asalkan nama penulis dan sumber asli disertakan. Karya ini dilisensikan di bawah Lisensi Creative Commons Attribution Share Alike 4.0 Internasional.

\section{A B S T R A C T}

Introduction: Menstrual pain problems are problems that are often complained of by women, especially during their teens. This condition can get worse if accompanied by unstable psychological conditions, such as stress, depression, excessive anxiety, and excessive sadness or happiness.

Objectives: The purpose of this study was to determine the relationship of physical activity, family history of dysmenorrhea and anxiety with dysmenorrhea in adolescents at SMK Wijaya Kusuma, South Jakarta in 2020.

Method: The design of this study used analytical methods with cross sectional research designs. The population of this research is the Young Women at Smk Wijaya Kusuma. So the sample needed is 86 respondents.

Result: Chi square hypothesis test results obtained p-value of 0.035 , it can be concluded that there is a relationship between physical activity and dysmenorrhea in adolescents at SMK Wijaya Kusuma, South Jakarta in 2020. In addition, an Odds Ratio (OR) score of 3.874 means that respondents routinely perform physical activity had 3,874 times the chance to experience mild dysmenorrhea compared with respondents who did not routinely engage in physical activity. There is a relationship of anxiety towards dysmenorrhea in adolescents in Smk Wijaya Kusuma, South Jakarta in 2020 with a p-value of 0.012 and an Odds Ratio (OR) of 3.539.

Conclution: The conclusion is that there is a relationship between physical activity, family history of dysmenorrhea and anxiety with dysmenorrhea in adolescents at SMK Wijaya Kusuma, South Jakarta in 2020. Suggestions for adolescents to be able to routinely carry out daily physical activities such as exercising and doing homework in order to reduce dysmenorrhea.

Keyword: Dysmenorrhea, Family History, Worry, Physical Activity. 


\section{SIMFISIS Jurnal Kebidanan Indonesia}

Volume 01, Nomor 01, Agustus 2021

\section{Pendahuluan}

Kesehatan reproduksi untuk seorang wanita merupakan komponen yang amat penting. Wanita memiliki sistem reproduksi yang sangat rentan terhadap gangguan yang dapat menimbulkan masalah pada kesehatan reproduksinya. ${ }^{1}$ Permasalahan nyeri haid adalah permasalahan yang sering dikeluhkan saat perempuan datang ke dokter atau tenaga kesehatan yang berkaitan dengan haid. Kondisi ini dapat bertambah parah bila disertai dengan kondisi psikis yang tidak stabil, seperti stres, depresi, cemas berlebihan, dan keadaan sedih atau gembira yang berlebihan. Pada usia 17-24 tahun sering terjadi dismenore,karena pada usia itu terjadioptimalisasi fungsi rahim. ${ }^{2}$

Gangguan ini tidak boleh didiamkan karena dapat berdampak serius. Dampak yang terjadi jika nyeri haid (dismenore) tidak ditangani adalah gangguan aktifitas hidup sehari-hari, gelisah, depresi, Retrograd menstruasi (menstruasi yang bergerak mundur), infertilitas (kemandulan), kehamilan tidak terdeteksi, ektopik pecah, kista pecah, perforasi rahim dari IUD dan infeksi. Gangguan yang umumnya terjadi pada perempuan saat menstruasi adalah darah menstruasi yang sangat banyak (menorrhagia) dan timbul rasa sakit saat menstruasi (dismenore). ${ }^{3}$

Tingginya angka kejadiandismenore pada remaja kurang mendapat perhatian dari diri sendiri, karena menerima rasa sakit itusebagai hal yang wajar. Padahal dismenore dapat mengakibatkan seseorang menjadi lemas tidak bertenaga, pucat, kurangnya konsentrasi, sehingga berdampak negatif pada kegiatan sehari-hari dan bahkan menjadi salah satualasan tersering wanita tidak melakukan aktifitas (sekolah, kerja,dan lain-lain). Dismenore cenderun gterjadi lebih sering dan lebih hebat, pada gadis remaja yang mengalami kegelisahan, ketegangan dankecemasan. Rasa nyeri dismenore memberikan dampak negatif padakualitas hidup penderita serta status ekonomi diri sendiri penderita dan keluarganya, terganggu aktivitas sehari-hari, ketinggalan mata pelajaran atau kuliah, endometrosis, gangguan psikologis. ${ }^{4}$ Dari data yang didapatkan kejadian sebesar 1.769 .425 jiwa (90\%) wanita yang mengalami dismenore dengan 10 -15\% mengalami dismenore berat. Angka kejadian dismenore di dunia sangat besar. Rata-rata hampir lebih dari 50\% wanita mengalaminya. di inggris sebuah penelitian bahwa 10\% dariremaja sekolah lanjut absen 1-3 harisetiap bulannya karena menderita dismenore. ${ }^{5}$

Penelitian yang bertujuan untuk mengetahui kejadian dismenore pada remaja telah banyak dilakukan. Hasil penelitian di amerika Serikat pada tahun 2012 untuk mengetahui kejadiandismenore primer pada wanita umur 12 - 17 tahun adalah 59,7\% dengan derajat kesakitan $49 \%$ dismenore ringan, $37 \%$ dismenore sedang, dan $12 \%$ dismenore berat. ${ }^{6}$ Seorang perempuan akan sering mengalami keluhankeluhan menjelang menstruasi atau disebut premenstrual syndrome yang biasanya dimulai satu minggu sampai dengan beberapa hari sebelum datangnya menstruasi dan menghilang sesudah menstruasi datang walaupun kadang terus berlanjut sampai menstruasi berhenti. Sebanyak 95\% perempuan Indonesia mengalami gejala premenstruasi. Sindrom premenstruasi sedang hingga berat diderita berturut-turut oleh 3,9\% dan 1,1\%, angka tersebut lebih rendah dibanding perempuan Barat, Cina ataupun Jepang. ${ }^{7}$

Gejala dari premenstrual syndrome meliputi sakit kepala, nyeri perut (dismenorea), sulit konsentrasi, diare, konstipasi, buah dada nyeri, sering merasa lelah, berdebar-debar, depresi, mudah tersinggung, mudah marah, tegang, gelisah, sensitif, rasa cemas, perasaan labil. Bahkan beberapa perempuan mengalami depresi ringan sampai sedang saat sebelum mendapat menstruasi. ${ }^{8}$ Gejala premenstrual syndrome yang paling sering terjadi pada kebanyakan perempuan adalah dismenorea. Dismenorea yaitu nyeri uteri pada waktu menstruasi. Studi longitudinal dari Swedia melaporkan dismenorea terjadi pada 90\% wanita yang berusia kurang dari 19 tahun dan $67 \%$ wanita yang berusia 24 tahun. Angka kejadian dismenorea di Indonesia sekitar 54,89\%. ${ }^{9}$ 


\section{SIMFISIS Jurnal Kebidanan Indonesia}

Volume 01, Nomor 01, Agustus 2021

Salah satu faktor psikologis yang diduga dapat memicu terjadinya dismenorea adalah kecemasan. Seseorang dikatakan mengalami kecemasan saat mengalami gejala-gejala kekhawatiran terhadap sesuatu hal yang tidak pasti, sulit berkonsentrasi, gelisah, tidak dapat bersikap santai, kesulitan tidur atau mengalami gangguan tidur, pucat, mudah letih, tubuh terasa lebih hangat, mual, sesak nafas serta sering buang air kecil. ${ }^{10}$

Berdasarkan Peraturan Pemerintah Republik Indonesia Nomor 61 Tahun 2014 tentang Kesehatan Reproduksi dalam pasal 11 dijelaskan bahwa pemerintah menerapkan Pelayanan Kesehatan Reproduksi Remaja bertujuan untuk mempersiapkan remaja agar menjalani kehidupan reproduksi sehat dan bertanggung jawab. Dalam hal ini pemerintah berupaya untuk meningkatkan kualitas Pelayanan Kesehatan Peduli Remaja (PKPR). Termasuk kualitas dalam memberikan informasi kesehatan remaja dan pelayanan konseling disemua tempat pelayanan kesehatan. Pelayanan kesehatan ibu, Pelayanan kesehatan anak dan Pelayanan kesehatan reproduksi perempuan dan keluarga berencana. ${ }^{11}$

Bidan ikut berperan dalam memberikan pelayanan kesehatan reproduksi. Selain itu, bidan juga bisa memberikan konseling sesuai dengan wewenangnya kepada wanita khususnya remaja yang mengalami gangguan terhadap kesehatan reproduksi. Ada sebagian masyarakat yang mempunyai pendapat bahwa nyeri haid dapat hilang dengan sendirinya apabila wanita bersangkutan telah menikah sehingga mereka membiarkan gangguan tersebut. ${ }^{12}$

Berdasarkan hasil studi pendahuluan yang dilakukan oleh peneliti di SMK Wijaya Kusuma tahun 2019. Dari hasil wawancara kepada 10 siswi ternyata hasilnya 10 siswi (100\%) mengatakan selalu mengalami nyeri pada saat menstruasi (dismenorea). Dengan menggunakan skala nyeri 10 poin diketahui, 2 siswi (20\%) diantaranya mengatakan nyeri berat (skalanyeri 7), 3 siswi (30\%) diantaranya mengatakan nyerisedang (skala nyeri 6), 3 siswi(30\%) mengatakan nyeri sedang (skala nyeri 5) dan 2 siswi (30\%) diantaranya mengatakan nyeri sedang (skalanyeri 4). Berdasarkan latar belakang tersebut peneliti tertarik untuk meneliti Hubungan Aktifitas Fisik, Riwayat Dismenore Keluarga Dan kecemasan Dengan Dismenore Pada Remajadi SMK Wijaya Kusuma Jakarta Selatan Tahun 2020. Tujuan dalam penelitian ini adalah untuk hubungan aktifitas fisik, riwayat dismenore keluarga dan kecemasan dengan dismenore pada remaja di SMK Wijaya Kusuma Jakarta Selatan Tahun 2020.

\section{Metode}

Penelitian ini menggunakan metode analitik dengan desain penelitian cross sectional. Cross sectional adalah suatu rancangan penelitian yang dilakukan untuk mengetahui pengaruh variabel independen dengan variabel dependen dimana pengukurannya dilakukan secara bersamaan atau sekaligus. ${ }^{13}$ Data yang digunakan adalah data primer dengan cara menyebarkan kuesioner ke siswi. Dalam penelitian ini hanya untuk mengetahui hubungan aktifitas fisik, riwayat dismenore keluarga dan kecemasandengan dismenore pada remaja di SMK Wijaya Kusuma Tahun 2020.

Alat ukur atau instrumen penelitian adalah alat atau fasilitas yang digunakan oleh peneliti dalam mengumpulkan data agar pekerjaannya lebih mudah dan hasilnya lebih baik, sistematis dan mudah diolah Kuesioner disusun dan dikembangkan berdasarkan literatur yang relevan dan sesuai dengan variabel yang merujuk kepada BAB II. ${ }^{14}$ Penelitian ini akan dilaksanakan di SMK Wijaya Kusuma tahun 2020 .

Populasi adalah keseluruhan objek penelitian atau objek yang akan diteliti). Populasi adalah wilayah generalisasi yang terdiri atas obyek/subyek yang mempunyai kualitas dan karakteristik tertentu yang ditetapkan oleh peneliti untuk dipelajari dan kemudian ditarik kesimpulannya. ${ }^{15}$ populasi remaja putri di smk wijaya kusuma adalah sebanyak 597 siswi. Sampel adalah sebagian atau wakil dari populasi 


\section{SIMFISIS Jurnal Kebidanan Indonesia}

Volume 01, Nomor 01, Agustus 2021

yang diteliti. sampel merupakan bagian populasi yang akan diteliti atau sebagian jumlah dari karakteristik yang dimiliki oleh populasi. sampel adalah bagian dari jumlah dan karakteristik yang dimiliki oleh populasi tersebut. Jadi sampel yang dibutuhkan adalah sebanyak 86 responden.

Teknik pengambilan sampel dalam penelitian ini dilakukan menggunakan metode Random sampling, menjelaskan teknik pengambilan sampling secara random atau acak di sebut random sampling, dan sampel yang di peroleh di sebut samplel random. Teknik random sampling ini hanya boleh digunakan apabila setiap unit atau anggota populasi itu bersikap homogen atau disumsikan homogen. Hal ini berarti setiap anggota populasi itu mempunyai kesempatan yang sangat untuk diambil sebagai sampel.

Sebelum kuesioner dibagikan terlebih dahulu peneliti menjelaskan tata cara pengisian kuesioner kepada responden. Peneliti menunggu sampai responden selesai mengisi pertanyaan yang diberikan. Kriteria inklusi adalah karakteristik umum subjek penelitian dari suatu populasi target yang terjangkau yang akan diteliti. ${ }^{16}$ Remaja Putri yang sudah mengalami menstuasi di SMK Wijaya Kusuma. Remaja Putri di SMK Wijaya Kusuma yang bersedia menjadi responden. Kriteria non inklusi adalah karakteristik yang tidak termasuk dalam penelitian. Kriteria dalam penelitian ini remaja putri yang tidak terkena anemia. Kriteria eksklusi adalah kriteria dimana subjek tidak bisa menjadi responden karena tidak memenuhi syarat penelitian, menolak menjadi responden atau keadaan yang tidak memungkinkan dilakukan penelitian.

Uji coba instrumen di lahan merupakan bagian dari proses validasi empirik. Melalui uji coba tersebut, instrumen diberikan kepada sejumlah responden sebagai sampel uji coba yang mempunyai karakteristik sama atau ekivalen dengan karakteristik populasi penelitian. Jawaban atau respon dari sampel uji coba merupakan data empiris yang akan dianalisis untuk menguji validitas empiris atau validitas kriteria yang dikembangkan.

Validitas yang digunakan dalam penelitian ini content validity yaitu menggambarkan kesesuaian sebuah pengukur data dengan apa yang akan diukur. Dan digunakan dengan meghitung korelasiantara setiap skor butir instrument dengan skor total. Dalam melakukan pengujian validitas digunakan alat ukur berupa program komputerisasi, dan jika suatu alat ukur mempunyai korelasi yang signifikan antara skor item terhadap skor totalnya maka dikatakan alat skor tersebut adalah valid. Pengolahan data dilakukan setelah pengumpulan data dan data akan diatur dengan cara menggunakan Program Statistic Product for Social and Science. Interprestasi data disajikan dalam bentuk narasi sehingga memudahkan pemahaman terhadap hasil penelitian, yaitu ungkapkan bahwa berdasarkan teori yang dapat dilihat Hubungan aktifitas fisik, riwayat dismenore keluarga dan Kecemasan dengan dismenore pada remaja di SMK Wijaya Kusuma Jakarta Selatan tahun 2020.

\section{Hasil}

Tabel 1. Distribusi Frekuensi Variabel Dismenore, Kecemasan, Aktivitas Fisik, Riwayat Disminore Keluarga pada Remaja di SMK Wijaya Kusuma Jakarta Selatan Tahun 2020

\begin{tabular}{ccc}
\hline Variabel & Frekuensi (f) & Presentase (\%) \\
\hline Dismenore & 36 & 41,9 \\
Berat & 50 & 58,1 \\
Ringan & 31 & 36,0 \\
Kecemasan & & \\
Cemas & & \\
\hline
\end{tabular}


Tidak Cemas

Aktivitas Fisik

Tidak Rutin

Rutin

Riwayat Dismenore Keluarga

Mengalami

Tidak Mengalami
55

64,0

$33 \quad 38,4$

$53 \quad 61,6$

$36 \quad 41,9$

Sumber: Data Primer, 2020

Berdasarkan tabel 1 diketahui bahwa lebih banyak responden di SMK Wijaya Kusuma Jakarta Selatan mengalami dismenore ringan, yaitu sebanyak $50(58,1 \%)$ responden. Diketahui bahwa lebih banyak responden di SMK Wijaya Kusuma Jakarta Selatan tidak mengalami kecemasan, yaitu sebanyak $55(64,0 \%)$ responden. Diketahui bahwa lebih banyak responden di SMK Wijaya Kusuma Jakarta Selatan rutin melakukan aktivitas fisik, yaitu sebanyak $53(61,6 \%)$ responden. Diketahui bahwa lebih banyak responden di SMK Wijaya Kusuma Jakarta Selatan tidak memiliki riwayat dismenore pada keluarga, yaitu sebanyak $50(58,1 \%)$ responden.

Pada penelitian ini analisa data menggunakan tabel dan narasi dimana hasilnya menggunakan analisis data dalam bentuk univariat yaitu menganalisis setiap variabel dari hasil penelitian yang menghasilkan distribusi dan frekuensi dari tiap variabel. Setelah setiap alternatif jawaban diketahui selanjutnya diadakan persentase dengan cara membagi frekuensi setiap jawaban (f) dengan jumlah soal (N) kemudian dikalikan 100.

Analisis dilakukan untuk mengetahui variabel bebas yang paling dominan berhubungan terhadap variabel terikat. Analisis multivariat yang akan peneliti lakukan yaitu menggunakan analisis regresi logistik ganda. Analisis regresi logistik ganda ini merupakan analisis hubungan antara beberapa variabel independen terhadap satu variabel dependen.

Tabel 2. Hubungan Aktifitas Fisik, Riwayat Dismenore Keluarga dan Kecemasan dengan Dismenore pada Remaja di SMK Wijaya Kusuma Jakarta Selatan Tahun 2020

\begin{tabular}{|c|c|c|c|c|c|c|c|c|}
\hline \multirow{3}{*}{ Variabel } & \multicolumn{4}{|c|}{ Dismenore } & \multirow{2}{*}{\multicolumn{2}{|c|}{ Total }} & \multirow{3}{*}{$P$-value } & \multirow{3}{*}{ OR } \\
\hline & \multicolumn{2}{|c|}{ Berat } & \multicolumn{2}{|c|}{ Ringan } & & & & \\
\hline & f & $\%$ & $\mathbf{f}$ & $\%$ & f & $\%$ & & \\
\hline \multicolumn{9}{|l|}{ Kecemasan } \\
\hline Cemas & 19 & 61,3 & 12 & 38,7 & 31 & 100 & \multirow{3}{*}{0,012} & \multirow{3}{*}{$\begin{array}{c}3,539 \\
(1,408-8,895)\end{array}$} \\
\hline Tidak Cemas & 17 & 30,9 & 38 & 69,1 & 55 & 100 & & \\
\hline Jumlah & 36 & 41,9 & 50 & 58,1 & 86 & 100 & & \\
\hline \multicolumn{9}{|l|}{ Aktivitas Fisik } \\
\hline Tidak Rutin & 19 & 57,6 & 14 & 42,4 & 33 & 100 & \multirow{3}{*}{0,035} & \multirow{3}{*}{$\begin{array}{c}3,874 \\
(1,169-7,066)\end{array}$} \\
\hline Rutin & 17 & 32,1 & 36 & 67,9 & 53 & 100 & & \\
\hline Jumlah & 36 & 41,9 & 50 & 58,1 & 86 & 100 & & \\
\hline \multicolumn{9}{|l|}{ Riwayat } \\
\hline \multicolumn{9}{|l|}{ Dismenore } \\
\hline \multicolumn{9}{|l|}{ Keluarga } \\
\hline Mengalami & 21 & 58,3 & 15 & 41,7 & 36 & 100 & \multirow{3}{*}{0,016} & \multirow{3}{*}{$\begin{array}{c}3,267 \\
(1,332-8,012)\end{array}$} \\
\hline $\begin{array}{l}\text { Tidak } \\
\text { Menoalami }\end{array}$ & 15 & 30,0 & 35 & 70,0 & 50 & 100 & & \\
\hline Jumlah & 36 & 41,9 & 50 & 58,1 & 86 & 100 & & \\
\hline
\end{tabular}

Sumber: Data Primer, 2020 


\section{SIMFISIS Jurnal Kebidanan Indonesia}

Volume 01, Nomor 01, Agustus 2021

Berdasarkan tabel 2 diketahui bahwa $19(61,3 \%)$ responden tidak mengalami kecemasan dan mengalami dismenore ringan. Sedangkan ada $38(69,1 \%)$ responden mengalami kecemasan dan mengalami dismenore berat. Hasil uji hipotesis chi square diperoleh p-value sebesar 0,012, maka dapat disimpulkan bahwa ada hubungan kecemasan terhadap dismenore pada remajaDI SMKWijaya Kusuma Jakarta Selatan tahun 2020. Selain itu, diperoleh nilai Odds Ratio (OR) sebesar 3,539, artinya responden tidak mengalami kecemasan mempunyai peluang 3,539 kali untuk mengalami dismenore ringan dibandingkan dengan responden mengalami kecemasan. Diketahui bahwa $19(57,6 \%)$ responden rutin melakukan aktivitas fisik dan mengalami dismenore ringan. Sedangkan ada $36(67,9 \%)$ responden tidak rutin melakukan aktivitas fisik dan mengalami dismenore berat. Hasil uji hipotesis chi square diperoleh p-value sebesar 0,035, maka dapat disimpulkan bahwa ada hubungan aktivitas fisik terhadap dismenore pada REMAJA di SMK Wijaya Kusuma Jakarta Selatan tahun 2020. Selain itu, diperoleh nilai Odds Ratio (OR) sebesar 3,874, artinya responden rutin melakukan aktivitas fisikmempunyai peluang 3,874 kali untuk mengalami dismenore ringan dibandingkan dengan responden yang tidak rutin melakukan aktivitas fisik. Diketahui bahwa $21(58,3 \%)$ responden tidak memiliki riwayat dismenore pada keluarga dan mengalami dismenore ringan. Sedangkan ada 35 (70,0\%)responden memiliki riwayat dismenore pada keluarga dan mengalami dismenore berat. Hasil uji hipotesis chi square diperoleh p-value sebesar 0,016, maka dapat disimpulkan bahwa ada hubungan riwayat dismenore keluarga terhadap dismenore pada Remaja di SMK Wijaya Kusuma Jakarta Selatan tahun 2020. Selain itu, diperoleh nilai Odds Ratio (OR) sebesar 3,267, artinya responden tidak memiliki riwayat dismenore pada keluargamempunyai peluang 3,267 kali untuk mengalami dismenore ringan dibandingkan dengan responden yang memiliki riwayat dismenore pada keluarga.

\section{Pembahasan}

\section{Hubungan Kecemasan Terhadap Dismenore pada remaja di SMK Wijaya Kusuma Jakarta Selatan Tahun 2020}

Hasil penelitian ini diketahui bahwa $19(61,3 \%)$ responden tidak mengalami kecemasan dan mengalami dismenore ringan. Sedangkan ada $38(69,1 \%)$ responden mengalami kecemasan dan mengalami dismenore berat. Hasil uji hipotesis chi square diperoleh p-value sebesar 0,012, maka dapat disimpulkan bahwa ada hubungan kecemasan terhadap dismenore pada remaja di SMK Wijaya Kusuma Jakarta Selatan tahun 2020. Selain itu, diperoleh nilai Odds Ratio (OR) sebesar 3,539, artinya responden tidak mengalami kecemasan mempunyai peluang 3,539 kali untuk mengalami dismenore ringan dibandingkan dengan responden mengalami kecemasan.

Hasil penelitian ini sejalan dengan penelitian lainnya, diperoleh dari uji hipotesis menunjukkan bahwa terdapat hubungan yang signifikan antara tingkat kecemasan dengan kejadian dismenorea. Berdasarkan hasil analisis menggunakan teknik analisis regresi linear sederhana terhadap data tingkat kecemasan dan kejadian dismenorea, diperoleh p-value $0,000<0,05$ dan $\mathrm{R}$ sebesar 0,540 . Hal ini berarti tingkat kecemasan dapat digunakan sebagai prediktor untuk memprediksi kejadian dismenorea pada remaja putri. Menurut hasil perhitungan analisis regresi tersebut maka hipotesis yang diajukan dalam penelitian ini dapat diterima yaitu ada hubungan positif yang signifikan dan memiliki kekuatan korelasi yang sedang antara tingkat kecemasan dengan kejadian dismenorea pada remaja putri. ${ }^{17}$ Hubungan antara tingkat kecemasan dengan kejadian dismenorea dalam penelitian ini menunjukkan semakin tinggi tingkat kecemasan maka kejadian dismenorea pada remaja putri semakin tinggi. Hasil penelitian ini 
mendukung pernyataan Affandi bahwa bila hiphotalamus mendapat pengaruh dari luar seperti cahaya, bau-bauan dan hal-hal psikologis seperti kecemasan maka mengakibatkan penyaluran RH berjalan secara tidak normal sehingga produksi FSH dan LH abnormal dan berdampak pada proses ovulasi terutama terjadi perubahan pola menstruasi. Bila frekuensi menstruasi meningkat, produksi prostaglandin semakin tinggi dan akan meningkatkan kejadian dismenorea. ${ }^{18}$

Menurut asumsi peneliti, pada dismenorea, faktor psikis sangat berpengaruh, nyeri dapat dibangkitkan atau diperberat oleh keadaan psikis penderita. Keadaan psikis ini dapat berupa kecemasan.

\section{Hubungan Riwayat Dismenore Keluarga terhadap Dismenore pada Remaja di SMK Wijaya Kusuma Jakarta Selatan}

Hasil penelitian ini diketahui bahwa $21(58,3 \%)$ responden tidak memiliki riwayat dismenore pada keluarga dan mengalami dismenore ringan. Sedangkan ada $35(70,0 \%)$ responden memiliki riwayat dismenore pada keluarga dan mengalami dismenore berat. Hasil uji hipotesis chi square diperoleh pvalue sebesar 0,016, maka dapat disimpulkan bahwa ada hubungan riwayat dismenore keluarga terhadap dismenore pada remaja di SMK Wijaya Kusuma Jakarta Selatan tahun 2020. Selain itu, diperoleh nilai Odds Ratio (OR) sebesar 3,267, artinya responden tidak memiliki riwayat dismenore pada keluargamempunyai peluang 3,267 kali untuk mengalami dismenore ringan dibandingkan dengan responden yang memiliki riwayat dismenore pada keluarga.

Hasil ini sejalan dengan penelitian yang menemukan bahwa riwayat keluarga memiliki hubungan yang signifikan dengan dismenorea primer $(\mathrm{p}<0,05)$. Riwayat dismenore keluarga (ibu atau saudara perempuan kandung) merupakan salah satu faktor risiko dismenore. Kondisi anatomi dan fisiologis dari seseorang pada umumnya hampir sama dengan orang tua dan saudara-saudaranya. ${ }^{19}$ Dismenore sebagian besar dialami oleh seseorang yang mempunyai riwayat keluarga atau keturunan dismenore. Dua dari tiga wanita yang menderita dismenore mempunyai riwayat dismenore pada keluarganya. Wiknjosastro mengemukakan bahwa adanya riwayat keluarga dan genetik berkaitan dengan terjadinya dismenore primer yang berat. Peran keluarga dalam memberikan edukasi atau pengetahuan terkait menstruasi sebagai upaya preventif terhadap dismenore dapat memperkecil atau mencegah kejadian dismenore pada wanita. ${ }^{18}$

Menurut asumsi peneliti, riwayat dismenore pada keluarga merupakan faktor resiko yang tidak dapat diubah. Oleh karena itu, hal ini berpengaruh terhadap kondisi kesehatan anggota keluarga itu sendiri dan merupakan faktor resiko yang sangat mendukung terjadinya suatu penyakit yang sama di lingkungan keluarga tersebut.

\section{Hubungan Aktivitas Fisik terhadap Dismenore pada Remaja di SMK Wijaya Kusuma Jakarta Selatan Tahun 2020}

Hasil penelitian ini diketahui bahwa $19(57,6 \%)$ responden rutin melakukan aktivitas fisik dan mengalami dismenore ringan. Sedangkan ada $36(67,9 \%)$ responden tidak rutin melakukan aktivitas fisik dan mengalami dismenore berat. Hasil uji hipotesis chi square diperoleh p-value sebesar 0,035, maka dapat disimpulkan bahwa ada hubungan aktivitas fisik terhadap dismenore pada remaja di SMK Wijaya Kusuma Jakarta Selatan tahun 2020. Selain itu, diperoleh nilai Odds Ratio (OR) sebesar 3,874, artinya responden rutin melakukan aktivitas fisikmempunyai peluang 3,874 kali untuk mengalami dismenore ringan dibandingkan dengan responden yang tidak rutin melakukan aktivitas fisik. Pada penelitianpenelitian sebelumnya didapatkan hasil penelitian setelah dilakukan chi-square untuk mencari hubungan antara aktivitas fisik dengan dysmenorrhea primer pada siswi SMP. K. Harapan Denpasar 


\section{SIMFISIS Jurnal Kebidanan Indonesia}

Volume 01, Nomor 01, Agustus 2021

yang berusia 13-15 tahun diperoleh nilai $\mathrm{p}$ sebesar 0,000. Dari analisis data dengan mengguanakan metode uji chisquare, maka dapat disimpulkan $(\mathrm{p}<0,05)$ ini menunjukan bahwa ada hubungan yang signifikan antara aktivitas fisik dengan dysmenorrhea primer pada siswi SMP. K. Harapan Denpasar yang berusia 13-15 tahun. ${ }^{20}$

Kejadian dysmenorrhea akan meningkat dengan kurangnya aktivitas fisik selama menstruasi dan kurangnya olahraga, hal ini dapat menyebabkan sirkulasi darah dan oksigen menurun. Dampaknya pada uterus adalah aliran darah dan sirkulasi oksigen pun berkurang dan menyebabkan nyeri. Hal ini disebabkan saat melakukan olahraga tubuh akan menghasilkan endorphin. Hormon endorphin dihasilkan di otak dan susunan syaraf tulang belakang berfungsi sebagai obat penenang alami yang diproduksi otak sehingga dapat menimbulkan rasa nyaman. Menurut American College of Sport Medicine (ACSM) kebugaran fisik adalah suatu kemampuan seseorang melakukan aktivitas fisik. Seseorang yang bugar, metabolismenya pun akan bagus dan secara substansial untuk menghasilkan energi yang dibutuhkan oleh tubuh saat melakukan aktivitas fisik, memiliki tubuh yang bugar dapat mengurangi faktor resiko berbagai macam penyakit kronis. ${ }^{5}$

Menurut asumsi peneliti, rendahnya aktivitas fisik pada remaja dapat disebabkan oleh banyak penyebab, penyebabkan antara lain malas, bosan capek, tidak punya peralatan berolahraga, tidak ada waktu dan sebagainya. Dengan melakukan aktivitas fisik yang teratur atau melakukan olahraga tubuh akan menghasilkan endorphin. Hormon ini dapat berfungsi sebagai obat penenang alami yang diproduksi otak sehingga menimbulkan rasa nyaman.

\section{Kesimpulan}

Berdasarkan temuan penelitian, maka dapat disimpulkan Ada hubungan kecemasan, riwayat dismenore keluarga, aktivitas fisik terhadap dismenore pada remaja di SMK Wijaya Kusuma Jakarta Selatan Tahun 2020

Bagi Remaja di SMK Wijaya Kusuma Jakarta Selatan Diharapkan remaja rutin melakukan aktivitas fisik sehari-hari seperti berolahraga dan melakukan pekerjaan rumah, tidak mudah tersinggung dengan orang sekitar saya pada saat mengalami menstruasi yang mengganggu aktivitas/kegiatan, melakukan hal-hal yang positif seperti mengajak teman sebaya untuk belajar bersama atau berkumpul melakukan aktivitas yang menunjang karir di masa depan. Bagi SMK Wijaya Kusuma Jakarta Selatan diharapkan adanya petugas kesehatan yang turun langsung ke SMK Wijaya Kusuma Jakarta Selatan ke wilayah warga setempat untuk memberikan penyuluhan terkait dismenore, rutin melakukan aktivitas fisik secara bersama serta aktif terjun langsung menjelaskan mengenai pengendalian dismenore pada remaja.

\section{Konflik Kepentingan}

Menyatakan bahwa penelitian ini independen dari konflik kepentingan individu dan organisasi

\section{Ucapan Terima Kasih}

Terimakasih kepada semua responden dan semua pihak yang mendukung penelitian ini.

\section{Pendanaan}

Sumber pribadi. 


\section{SIMFISIS Jurnal Kebidanan Indonesia}

\section{References}

1. Manuaba I. Memahami Kesehatan Reproduksi Wanita. Jakarta: Arcan. 2010.

2. Arini D, Saputri DI, Supriyanti D, Ernawati D. Pengaruh Senam Yoga Terhadap Penurunan Intensitas Nyeri Haid Pada Remaja Mahasiswi Keperawatan Stikes Hang Tuah Surabaya. J Keperawatan. 2020.

3. Lestari NMSD. Pengaruh dismenorea pada remaja. Semin Nas FMIPA UNDIKSHA III. 2013.

4. Khotimah H, Kirnantoro K, Endang Cahyawati F. Pengetahuan Remaja Putri tentang Menstruasi dengan Sikap Menghadapi Dismenore Kelas XI di SMA Muhammadiyah 7, Yogyakarta. J Ners dan Kebidanan Indones. 2016. doi:10.21927/jnki.2014.2(3).136-140

5. Anurogo dan Wulandari. Cara Jitu Mengatasi Nyeri Haid. Offset. 2011.

6. Shinta D. Faktor-Faktor yang Berhubungan dengan Kejadian Dismenore pada Siswi SMA Negeri 2 Medan. J Gizi, Kesehat Reproduksi dan Epidemiol. 2014.

7. Faiqah S, Sopiatun R. Faktor-Faktor Yang Berhubungan Dengan Pre Menstrual Syndrome Pada Mahasiswa Tk Ii Semester Iii Jurusan Kebidanan Poltekkes Kemenkes Mataram. J Kesehat Prima. 2015.

8. Ussher JM. Premenstrual syndrome. In: Cambridge Handbook of Psychology, Health and Medicine, Second Edition. ; 2014. doi:10.1017/CBO9780511543579.217

9. Ulfa HM. Hubungan Tingkat Pengetahuan Tentang Dismenorea Dengan Sikap Dalam Mengatasi Dismenorea Pada Remaja Putri. Univ Sebel Maret Surakarta. 2010.

10. Oktaviana A, Imron R. Menurunkan nyeri dismenorea dengan kompres hangat. J Keperawatan. 2012. doi:10.1017/S0007114514000373

11. Peraturan Pemerintah RI. Peraturan Pemerintah Republik Indonesia Nomor 61 Tahun 2014 Tentang Kesehatan Reproduksi. Implement Sci. 2014. doi:10.4324/9781315853178

12. Pinem S. Kesehatan Reproduksi Dan Kontrasepsi.; 2014.

13. Notoatmodjo Soekidjo. Metodologi Penelitian Kesehatan. Jakarta: Rineka Cipta. Notoatmodjo, S. (2012). Metodologi Penelitian Kesehatan. Jakarta: Rineka Cipta.

14. Suharsimi A. Prosedur Penelitian: Suatu Pendekatan Praktik (Edisi Revisi). Jakarta: Rineka Cipta. 2013. doi:10.1017/CBO9781107415324.004

15. Sugiyono. Metode Penelitian Kombinasi (Mixed Methods).; 2017.

16. Nursalam. Metodologi Penelitian Ilmu Keperawatan :Pendekatan Praktis.; 2015. doi:10.1007/0-38736274-6 24

17. Sukmiati E. Hubungan antara Tingkat Kecemasan dengan Kejadian Dismenorea pada Remaja Putri Kelas VII di SMPN 1 Ciwidey Kabupaten Bandung. J Med Cendikia. 2017.

18. Prawirohardjo S. Ilmu Kebidanan Sarwono Prawirohardjo. Ed Ke-4 Jakarta Yayasan Bina Pustaka Sarwono Prawirohardjo. 2016. doi:10.1017/CBO9781107415324.004

19. Pande N, Purnawati S. Hubungan Antara Indeks Massa Tubuh (Imt) Dengan Dismenorea Pada Mahasiswi Fakultas Kedokteran Universitas Udayana. E-Jurnal Med Udayana. 2016.

20. Febriana et al. Hubungan Tingkat Aktivitas Fisik Dengan Dysmenorrhea Primer Pada Remaja Umur 13-15 Tahun Di SMP. K. Harapan Denpasar. Jurnal. 2015. doi:10.1587/transcom.2016SNP0020 